\title{
Reducing residual stresses and deformations in selective laser melting through multi- level multi-scale optimization of cellular scanning strategy
}

\author{
Mohanty, Sankhya; Hattel, Jesper Henri
}

\section{Published in:}

Proceedings of SPIE

Link to article, DOI:

$10.1117 / 12.2212490$

Publication date:

2016

Document Version

Publisher's PDF, also known as Version of record

Link back to DTU Orbit

Citation (APA):

Mohanty, S., \& Hattel, J. H. (2016). Reducing residual stresses and deformations in selective laser melting through multi-level multi-scale optimization of cellular scanning strategy. In B. Gu, H. Helvajian, \& A. Piqué (Eds.), Proceedings of SPIE (Vol. 9738). [97380Z] SPIE - International Society for Optical Engineering.

Proceedings of SPIE - The International Society for Optical Engineering https://doi.org/10.1117/12.2212490

\section{General rights}

Copyright and moral rights for the publications made accessible in the public portal are retained by the authors and/or other copyright owners and it is a condition of accessing publications that users recognise and abide by the legal requirements associated with these rights.

- Users may download and print one copy of any publication from the public portal for the purpose of private study or research.

- You may not further distribute the material or use it for any profit-making activity or commercial gain

- You may freely distribute the URL identifying the publication in the public portal 


\title{
Reducing residual stresses and deformations in selective laser melting through multilevel multiscale optimization of cellular scanning strategy
}

\author{
Sankhya Mohanty, Jesper Henri Hattel \\ Dept. of Mechanical Engineering, Technical University of Denmark, Produktionstorvet, \\ Kongens Lyngby, Denmark 2800
}

\begin{abstract}
Residual stresses and deformations continue to remain one of the primary challenges towards expanding the scope of selective laser melting as an industrial scale manufacturing process. While process monitoring and feedback-based process control of the process has shown significant potential, there is still dearth of techniques to tackle the issue. Numerical modelling of selective laser melting process has thus been an active area of research in the last few years. However, large computational resource requirements have slowed the usage of these models for optimizing the process.

In this paper, a calibrated, fast, multiscale thermal model coupled with a 3D finite element mechanical model is used to simulate residual stress formation and deformations during selective laser melting. The resulting reduction in thermal model computation time allows evolutionary algorithm-based optimization of the process. A multilevel optimization strategy is adopted using a customized genetic algorithm developed for optimizing cellular scanning strategy for selective laser melting, with an objective of reducing residual stresses and deformations. The resulting thermo-mechanically optimized cellular scanning strategies are compared with standard scanning strategies and have been used to manufacture standard samples.
\end{abstract}

Keywords: selective laser melting, optimized scan strategies, multiscale hybrid pseudoanalytical-3DADI modelling, thermo-mechanical analysis, multilevel optimization

\section{INTRODUCTION}

The importance of scan strategy in producing parts with SLM has been established across several studies [1] [2] [3] [4]. Thus several newer scan strategies have been proposed over the years, both for single layer as well as multiple layers [5] [6] [7] [8] [9] [10]. Research in process optimization of selective laser, however, has primarily been an experimental undertaking [1] [5] [11]. The usage of focused, high-power lasers as heat sources and the associated multi-physics in SLM provides a challenge for modelling large spatial and/or temporal domains. The resulting large computational requirements and calculation times have remained a bottleneck for most numerical modelling based optimization research [12] and consequently there is a scarcity of process optimization studies across literature.

However, recently developed faster solution techniques for the thermal model [13] as well as established model reduction techniques for the thermo-mechanical models [14] of selective laser melting provide fresh scope for undertaking numerical modelling based optimization studies. In this paper, several such smart techniques have been adapted to enable process optimization of the cellular scanning strategy for selective laser melting with an aim of reducing in-situ transient stresses as well as residual stresses and deformations.

Laser 3D Manufacturing III, edited by Bo Gu, Henry Helvajian, Alberto Piqué, Proc. of SPIE Vol. 9738, 97380Z · C 2016 SPIE · CCC code: 0277-786X/16/\$18 · doi: 10.1117/12.2212490 


\section{HYBRID MODELLING OF THERMO-MECHANICS IN SLM}

\subsection{Thermal Model}

While several approaches are found in literature dealing with the thermal aspect of the process, there is a tendency for these proposed models to be computationally expensive [12]. The high cooling rates associated with selective laser melting process promotes a conduction-dominated heat transfer in most of the material/part while the high temperatures facilitate radiative heat transfer. Albeit the small size and temporal existence of the melt pool, necessity of developing a thermal-fluid model capable of capturing convective mass and heat transfer exists especially if phenomena such as balling effect were to be simulated [15] [16] [17], and become particularly important for high Rayleigh number and high Péclet number materials such as steel. However, in the current study selective laser melting with Ti6Al4V alloy has been investigated in a process window wherein convective heat transfer effects can be successfully modeled via effective conductive properties, thereby allowing reduction of the multi-physics involved.

For the study documented in this paper, the thermal problem is simulated using a hybrid between the pseudoanalytical model and a 3D finite volume alternating direction implicit model. The pseudo-analytical model [13] aims to alleviate the computational and time burden, and has been developed based on the concepts of discrete numerical methods, surrogate models and analytical solutions. The 3D finite volume alternate direction implicit (3D FV ADI) model is a high-fidelity model developed for faster thermal calculations while still preserving accuracy (the accuracy is similar to Crank-Nicholson method and the theoretical basis can be found in [18] ).

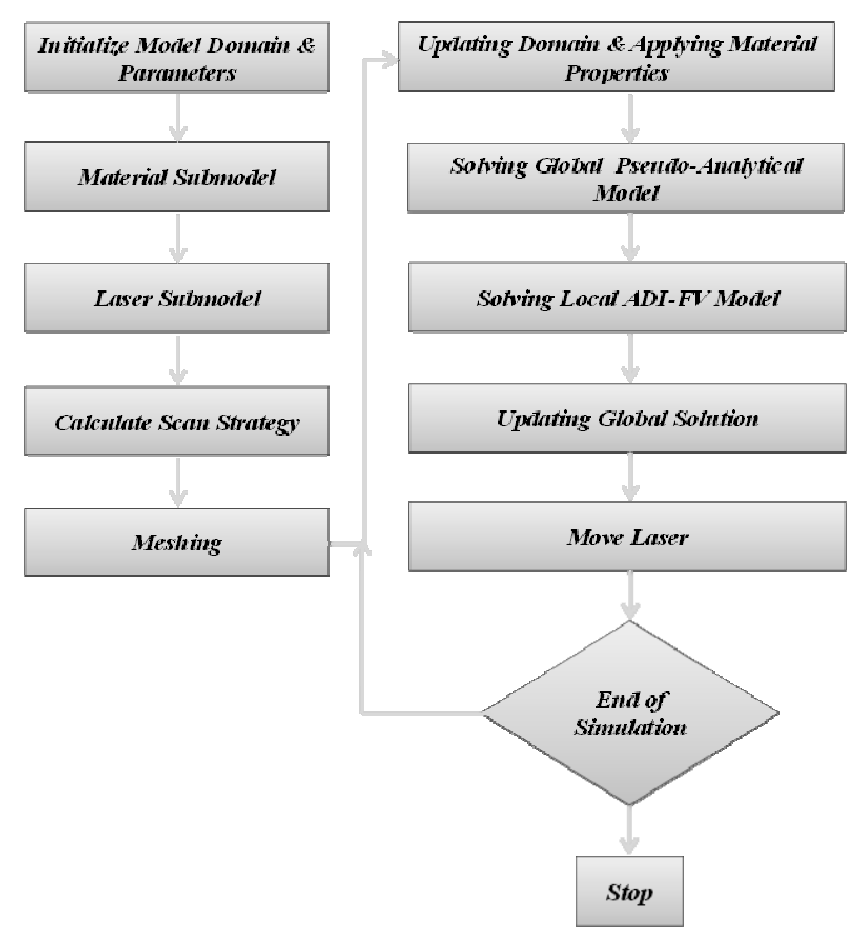

Figure 1 Algorithm for solving thermal problem with hybrid pseudo-analytical 3D FV ADI model

The hybrid pseudo-analytical 3D FV ADI model aims to combine the speed of pseudo-analytical model with the accuracy of 3D-ADI FV model to achieve fast and accurate thermal calculations. Figure 1 shows the algorithm for solving the thermal problem by combining the two models in a global-local approach. In the hybrid model, the pseudo-analytical model is used to solve the heat transfer problem in the global domain while the 3D FV 
ADI model is utilized locally centred around the laser beam. While the two models can be combined in various ways, the implementation carried out for this study is explained below via a validation study with respect to commercial finite element software.

\subsection{Validation of Hybrid Pseudo-analytical 3D FVADI Model}

Selective laser melting of a single powder layer of $50 \mu \mathrm{m}$ thickness is simulated for a domain size of $600 \mu \mathrm{m} \mathrm{X}$ $600 \mu \mathrm{m}$, wherein the domain is processed by an anti-parallel(zigzag) scanning strategy [19]. As reference, the problem is implemented in the commercial finite element software ABAQUS on a $10 \mu \mathrm{m}$ cubic mesh. The implemented hybrid model utilizes two distinct meshing strategy, a $25 \mu \mathrm{m}$ cubic mesh for the pseudo-analytical model, and a $5 \mu \mathrm{m}$ cubic mesh for the 3D FV ADI model. The thermal problem is first solved on the coarser mesh with the pseudo-analytical model, and the results are transferred to the local 3DFVADI model. The 3D FVADI model, which works with a smaller time step size, is then used to calculate the temperatures in a smaller local domain around the laser beam. The results from the 3DFVADI model are saved on the finer mesh as well as transferred to the global domain, which is then updated accordingly.

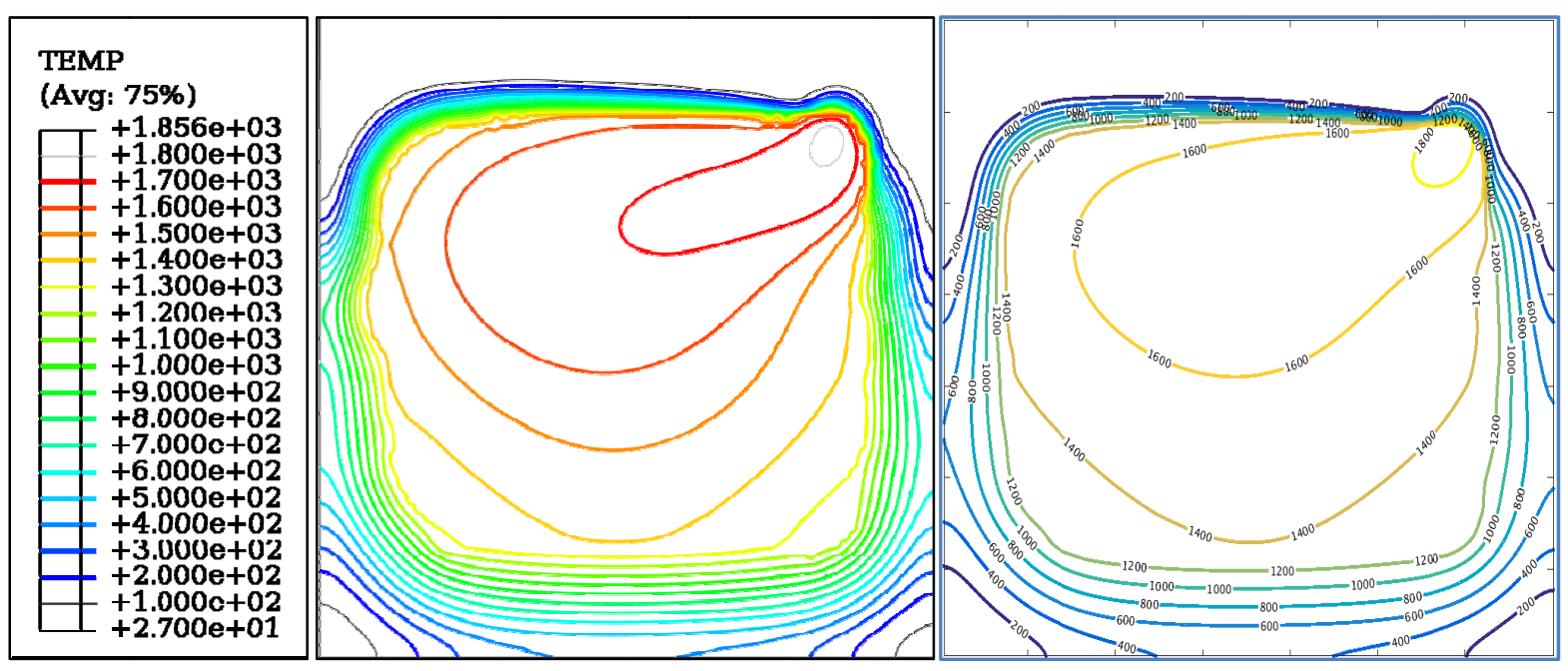

Figure 2 Temperature distribution calculated by ABAQUS model (left) and hybrid model (right) for antiparallel scanning strategy
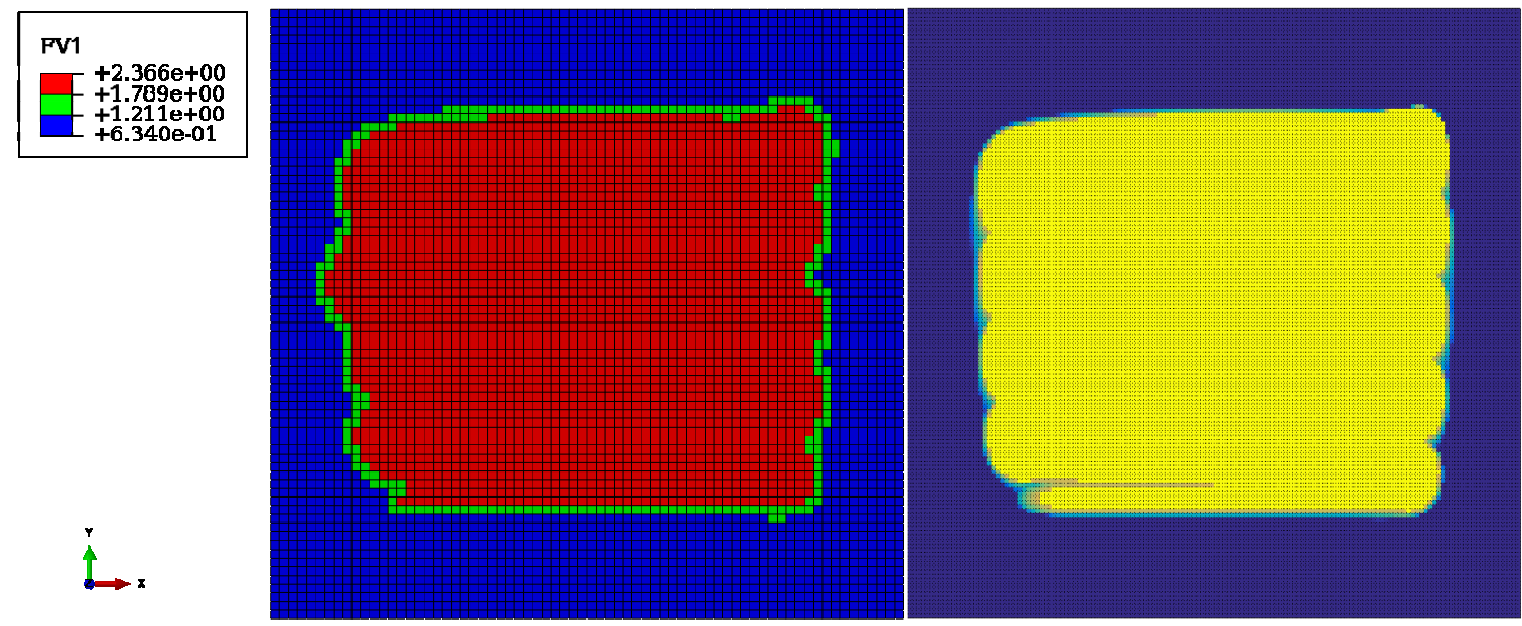

Figure 3 Molten and powder zone distribution calculated by ABAQUS model (left) and hybrid model (right) for antiparallel scanning strategy [ Blue- powder ; Red/Yellow - molten] 
Figure 2 shows the temperature field predicted by the ABAQUS implementation and the hybrid pseudoanalytical-3DADI model for the antiparallel scanning strategy. For this case, the scanned area is smaller than the modelled domain as is the case in real processing with selective laser melting. Figure 3 shows the molten and powder zones as predicted by the ABAQUS and hybrid model respectively.

\subsection{Mechanical Model}

Thermo-mechanical modelling of selective laser melting has been the subject of several publications [3] [20] [4] [21] [22] within the past half-decade with a focus on the residual stresses generated during processing and the resulting deformations upon unloading. As the computation time involved in thermo-mechanical modelling of SLM is usually quite large, the models often use some form of approximation to increase the speed of computation e.g. adding multiple layers together instead of one at a time [21].

Thermo-mechanics involved during SLM can be described using elasto-plastic constitutive models while solving the governing equations. The elastic behavior of the material being processed with SLM can be described using generalized Hooke's law, which describes an isotropic linear-elastic material. Due to high temperatures involved during SLM, the process description necessitates inclusion of plasticity models. Here, an isotropic hardening plasticity model is assumed based on von Mises flow criterion ( $\mathrm{J}_{2}$ flow theory), wherein yielding occurs when thrice the second invariant of stress deviator equals the square of the uniaxial yield strength of the material [23]

The primary modelling technique used to simulate the mechanical problem in selective laser melting involved applying user subroutines along with the finite element software ABAQUS. A domain of $500 \mu \mathrm{m} \mathrm{X} 500 \mu \mathrm{m} \mathrm{X}$ $50 \mu \mathrm{m}$ is chosen corresponding to the molten/re-solidified region in the above (validation) case and divided into elements of $10 \mu \mathrm{m}$ edge length. Selective laser melting on the domain is simulated using a sequential coupling between thermal and mechanical models. Temperature-dependent yield strength is supplied along with a temperature and equivalent plastic strain dependent hardening parameter. UMAT is used to set up the incremental finite element formulation with UHARD supplying the hardness parameter. USDFLD is used along with a tanh based smoothening function to capture the transition between powder and bulk (solid or liquid) material. The thermo-mechanical model thus formed is able to capture the thermal softening as well as strain hardening effects. Additionally, equivalent plastic strains are reset to zero in the current implementation once the temperature exceeds liquidus, thus allowing for stress relaxation and tracking the melt pool. Figure 4 shows the residual stresses and corresponding deformation in the processed domain upon cooling to room temperature.

\section{CELLULAR SCANNING STRATEGY OPTIMIZATION PROBLEM}

\subsection{Cellular Scanning Strategy}

One of the most successful strategies, applied as default in software accompanying SLM machines, is the island scanning strategy. Cellular scanning strategy is an extension of the idea behind island scanning strategy wherein instead of dividing a layer into multiple islands and processing them randomly, the layer to be produced is divided into combination of large cells of different standard shapes and sizes which are processed using optimized scanning strategies suitable for those cells shapes/sizes. Each such cell is further divided into smaller cells following similar idea of division, and the division process continues till standard unit cell sizes are reached which can be processed using scan strategies already available in literature such as anti-parallel, parallel, spiral, etc. These selected unit cell scanning strategies are then combined in an optimized manner to generate an appropriate sequence of processing for the next larger standard sized cell. Subsequently, the multiple optimized scanning strategies generated can be further combined in an optimized sequence to generate the scanning strategy for the next larger cell size. The process is better described in Figure $\mathbf{5}$ below wherein the division of a long bar into cells is shown. The generation of cellular scanning strategy then follows a bottom-up 
approach wherein the optimized scanning strategies for smaller sized cells form the inputs for generating optimized scanning strategy at higher cell size.
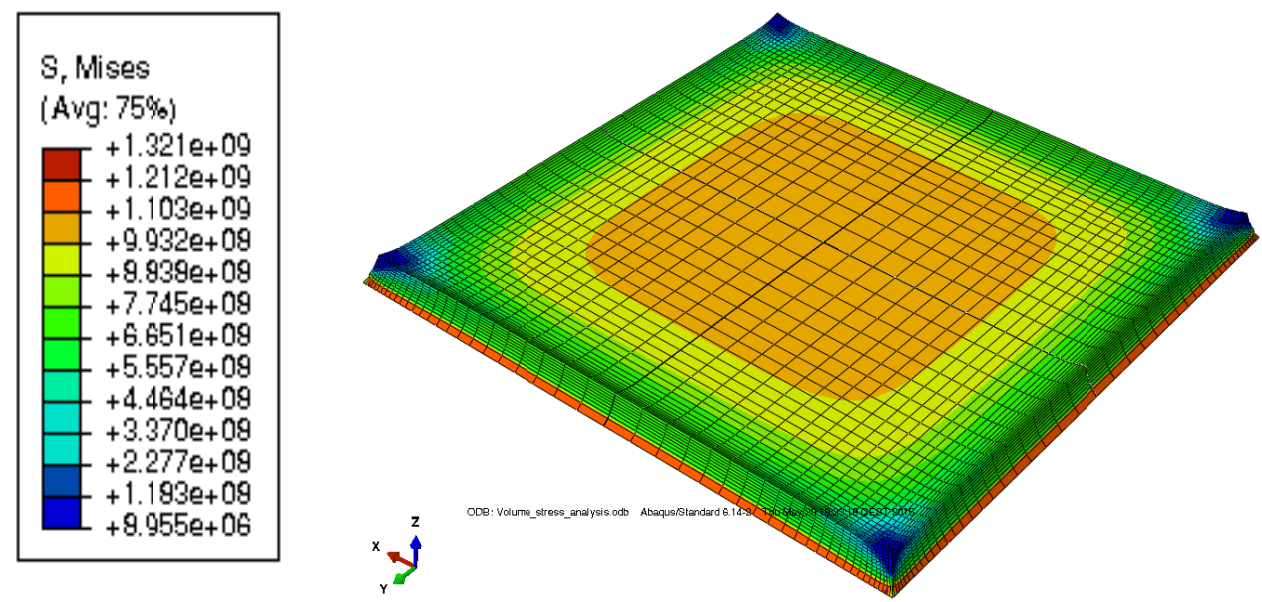

Figure 4 Residual stresses and deformation in a 500um X 500um domain processed by selective laser melting using antiparallel scanning strategy

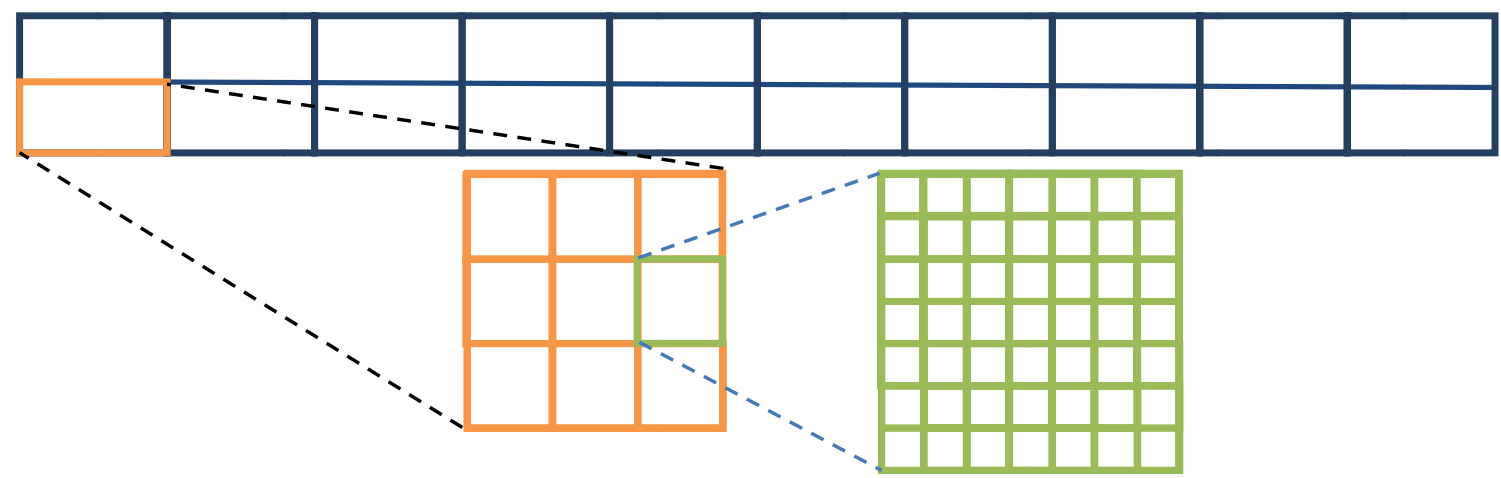

Figure 5 Dividing a long bar into cells for generating optimized cellular scanning strategy

The advantage of using cellular scanning strategy over standard island scanning strategy is that it allows for easier optimization as the time and effort required to solve a large problem is often more than solving equivalent multiple smaller problems. Moreover, upon optimizing the scanning strategies at a particular cell size level, the generated strategy can often be reused when optimizing at the higher cell size level. This will be furthered discussed in the subsequent section after describing what an optimized scanning strategy is. 


\subsection{Decomposing Cellular Scanning Strategy Optimization Problem}

Scanning strategy is not a directly quantifiable parameter and thus the first step towards optimization is formulating them in a quantitative manner. As the focus is on cellular scanning strategy, the optimization has been formulated into a combinatorial problem resembling the Travelling Purchaser Problem (TPP). Travelling Purchaser Problem is defined as the path a purchaser should take when visiting a fixed number of cities wherein in addition to the cost of travelling between different locations, each location has a list of available goods together with the price of each such good. The task is then to find, for a given list of articles, the route with the minimum combined cost of purchases and traveling.

Cellular scanning strategy can be seen to resemble the travelling purchaser problem, where the unit cells forming the processing domain are the cities/locations and the different unit cell scanning paths are the corresponding goods at each location. The current problem, however, differs from TPP as the effect of choosing a particular unit cell scanning path is not known a priori. Also, the current problem is asymmetric as the effect of choosing a particular unit cell scanning path is not necessarily the same if the particular path through the locations were to be travelled in reverse. Thus, the problem is apt to be solved as a multi-objective optimization problem with the sequence of travelling between locations and the net effect of choosing unit cell scanning strategies forming two objective functions to be minimized simultaneously.

Multi-objective optimization problems, however, are less trivial than single-objective optimization problems when the objectives become conflicting and result in non-dominated pareto fronts (i.e. when one of the objective functions cannot be improved without degrading the other objective function values). Although, it is eventually a more apt way of tackling the cellular scanning strategy optimization problem, the work here has attempted to split the aforementioned problem into individual single-objective problems. The intention is to develop more efficient techniques for solving the single objective problems (as some algorithms are better tuned to solve a particular type of problem compared to others), and subsequently combine them in a multi-level scheme. The cellular scanning strategy optimization problem has thus been formulated into two distinct combinatorial subproblems - modified travelling salesman problem and a unit-cell selection problem (assignment problem)

\subsubsection{Modified Travelling Salesman Problem}

The classical travelling salesman problem (TSP) [24] is a combinatorial problem, wherein a path needs to be determined through a given set of points in order to minimize the total path (e.g. the shortest time in which a salesman can visit $\mathrm{n}$ different cities). Formulating the first sub-problem into a classical TSP would result in a path corresponding to the shortest travel time between the different cells. As it will not draw on any processspecific knowledge, the resulting solutions might not be suitable for the larger optimization problem. More specifically, it will not be able to capture the asymmetric nature of the problem. However, coupling a numerical process model to the TSP while defining certain indicators for fitness based on results of the numerical model would add the necessary process knowledge.

\subsubsection{Unit Cell Selection Problem}

The unit cell selection problem is formulated as an assignment problem. A classical assignment problem is best explained with the following analogy

There are a number of agents and a number of tasks. Any agent can be assigned to perform any task, incurring some cost that may vary depending on the agent-task assignment. It is required to perform all tasks by assigning exactly one agent to each task and exactly one task to each agent in such a way that the total cost of the assignment is minimized. 
A generalization of this problem involves one agent being able to perform multiple tasks and vice versa. For the current problem, we assume the different unit cells to be the 'tasks' and the six scanning strategies shown in [19] to be the 'agents'. The cost of this assignment problem should be defined based on physical process characteristics, as it is framed to be the more rigorous of the two optimization sub-problems. Thus, for comparison between the different cellular scanning strategies, a dimensionless number $\Theta$ is defined and is given by

$$
\boldsymbol{\theta}=\left(\mathbf{T}_{\max } / \sigma_{\mathrm{temp}}^{\max }\right) *(\mathbf{1}+\mathbf{V}) /(\mathbf{1}+\mathbf{M})
$$

where $\mathrm{T}_{\max }$ is the maximum temperature during the simulation, $\sigma_{\text {temp }}^{\max }$ is the maximum value of standard deviation of temperature during simulation, $\mathrm{V}$ is the number of overheated zones at the end of simulation, and $\mathrm{M}$ is the number of molten zones at the end of simulation. Molten or overheated zones are classified based on the maximum value in the temperature history of the zone. More specifically,

Temperature $>$ Liquidus Temperature $\equiv$ Molten Zone

$$
\text { Temperature }>\frac{(\text { Liquidus Temperature }+ \text { Boiling Temperature })}{2} \equiv \text { Overheated Zone }
$$

The process-specific perspective behind selection of the different indicators is explained in [13], and is thus not discussed here. The usage of the $\Theta$ criteria as objective function for comparison of scanning strategies results in formulating the optimization as a minimization problem.

\subsection{Optimization of Selective Laser Melting}

For the current study on multilevel multiscale optimization of cellular scanning strategy, a domain of $10 \mathrm{~cm} \mathrm{X}$ $1 \mathrm{~cm}$ was chosen, which was divided into 40 cells of $5 \mathrm{~mm} X 5 \mathrm{~mm}$ each. Each such $5 \mathrm{~mm}$ square cell was further divided into unit cells of $500 \mu \mathrm{m}$ X $500 \mu \mathrm{m}$ which were to be processed using one of six standard scanning paths. The processing parameters used for simulation as well as experiments are given in Table 1.

On the lowest level and scale, the optimization problem involved generation of processing sequences of the $500 \mu \mathrm{m}$ X $500 \mu \mathrm{m}$ unit cells in the $5 \mathrm{~mm}$ X $5 \mathrm{~mm}$ domain. The next optimization level involved selection of scanning strategies for the unit cells for the multiple optimized processing sequences generated. Optimization at this scale was performed iteratively between the two levels for three successive optimization runs after which the results were carried over to the next higher scale.

On the lower level of the higher scale, the optimization problem involved generation of processing sequence of the $5 \mathrm{~mm}$ X $5 \mathrm{~mm}$ cells in the $10 \mathrm{~cm} \times 1 \mathrm{~cm}$ domain. Thereafter, the next level involved selection of scanning strategies of the $5 \mathrm{~mm}$ X $5 \mathrm{~mm}$ cells from the results carried over from the previous scale. Similar to the previous scale, the optimization was performed iteratively between the two levels for three successive optimization runs.

At the end of successful optimization at each scale, thermo-mechanical analysis was performed on the two generated scanning strategies with best numerically computed fitness values to ensure the validity of the optimization results. The limited number of thermo-mechanical simulations was due to the large computation time associated with each such simulation. Upon completion of the optimization procedure, the generated scan strategies were utilized to produce the $10 \mathrm{~cm}$ X $1 \mathrm{~cm}$ component by selective laser melting (as shown in Figure 6). 
Table 1 Processing parameters for selective laser melting with optimized cellular scanning strategy

\begin{tabular}{ll}
\hline Parameter & Values \\
\cline { 2 - 2 } Power & $120 \mathrm{~W}$ \\
FWHM & $80 \mathrm{e}-6 \mathrm{~m}$ \\
Chamber Temperature & $150 \mathrm{C}$ \\
Scan speed & $800 \mathrm{~mm} / \mathrm{s}$ \\
Hatch spacing & $80 \mathrm{e}-6 \mathrm{~m}$ \\
\hline
\end{tabular}

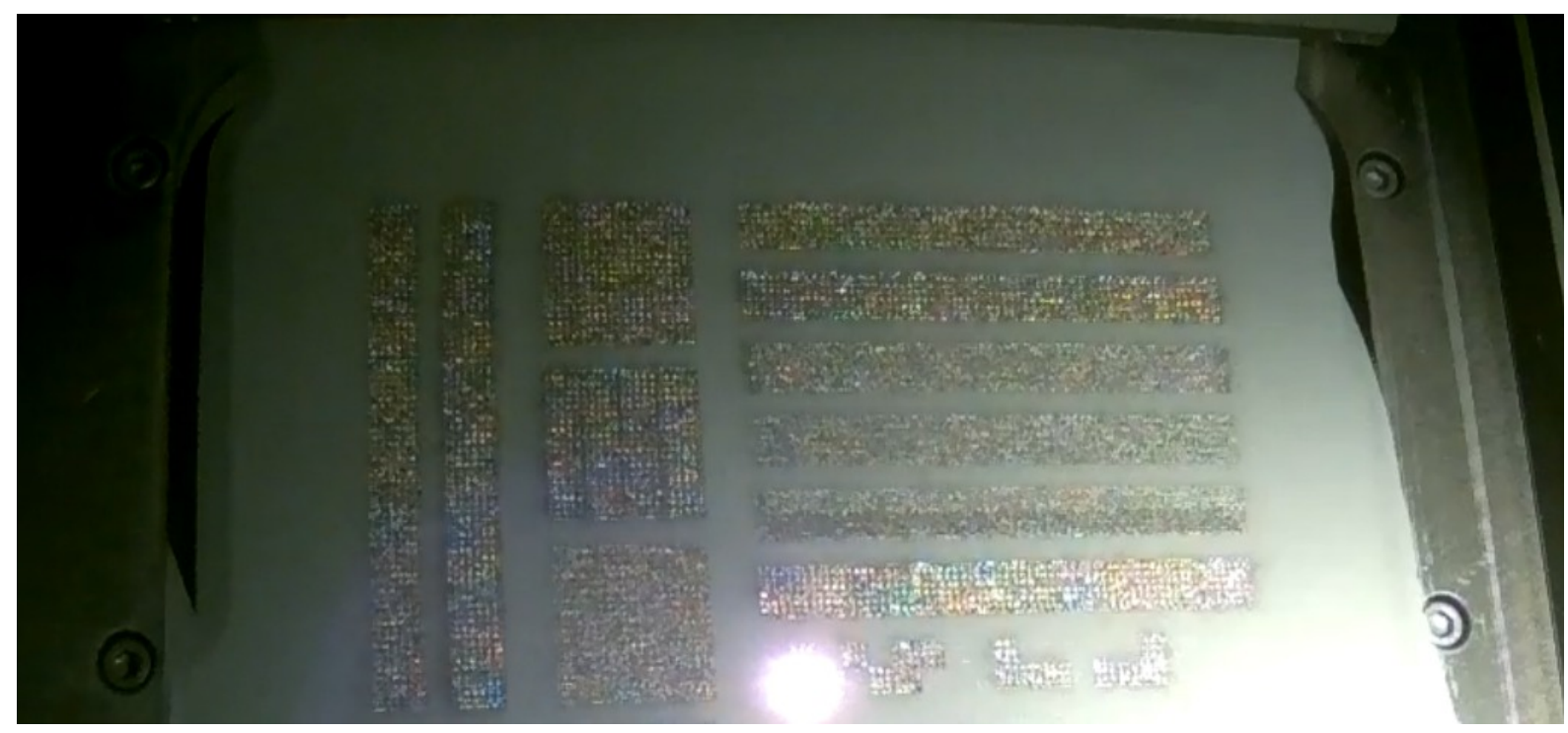

Figure 6 Manufacturing components by selective laser melting using optimized cellular scanning strategies

\section{RESULTS \& DISCUSSION}

The cellular scanning strategies generated through the optimization study have been used for manufacturing along with several control cases wherein the processing sequence is linear and/or unit cell scanning strategies have been fixed to be parallel scanning strategy. The optimization of the cellular scanning strategies has been aimed towards reducing the transient as well as residual stresses in components as well as resulting deformations. However, the control cases (corresponding to a randomized island scanning strategy) might lead to high residual stresses and localized deformations. Figure 7 shows delamination and deformations in one of the control cases during manufacturing of the $10 \mathrm{~cm} \mathrm{X} 1 \mathrm{~cm}$ bars wherein non-optimized temperature fields led to high localized stress concentrations resulting in localized deformation during cooling.

A closer look at the bars manufactured using control scanning strategy and an optimized cellular scanning strategy can be obtained in Figure 8 and Figure 9 respectively. The surface of the bar manufactured with the parallel scanning strategy (Figure 8) shows several areas of porosity containing unconsolidated powder particles. It is possible to observe several flat single track features in this surface layer. 


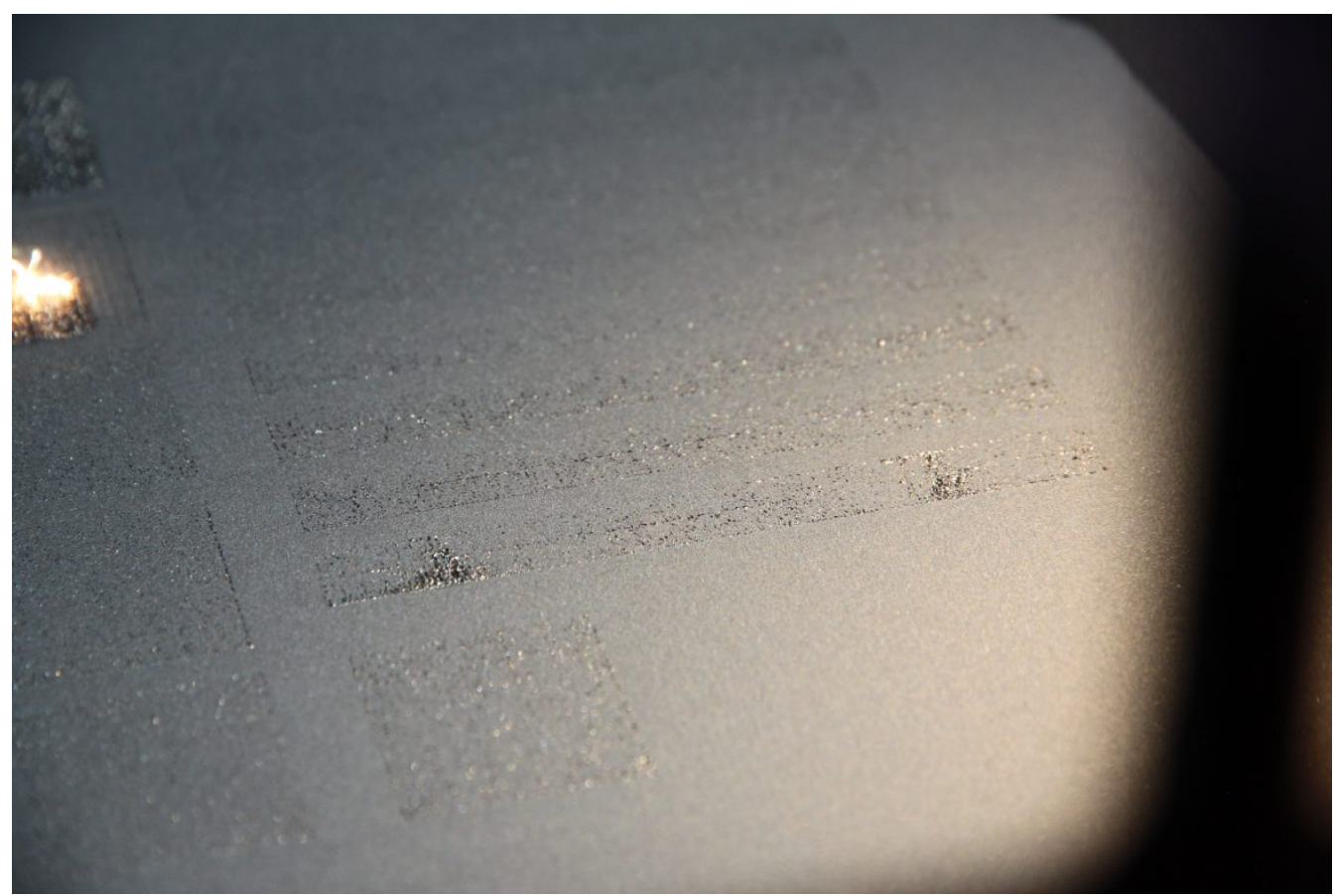

Figure 7 Deformation upon cooling in bars manufactured using control scanning strategy as opposed to no deformations in those manufactured by optimized cellular scanning strategies

In contrast, the surface of the bar manufactured using the optimized cellular scanning strategy (Figure 9) shows no immediate porosities and suggests full consolidation. The processing of adjacent unit cells using different scanning strategies is apparent from the patterns observed on this surface layer. The surface generated by the optimized cellular scanning strategy, however, has significant roughness as certain unit cell scanning strategies can be seen to promote balling effect. Nonetheless, while comparing the suitability of the optimized cellular scanning strategy over the control strategy, it should be considered that the objective functions used to evaluate fitness of scanning strategies did not contain information regarding surface roughness. 


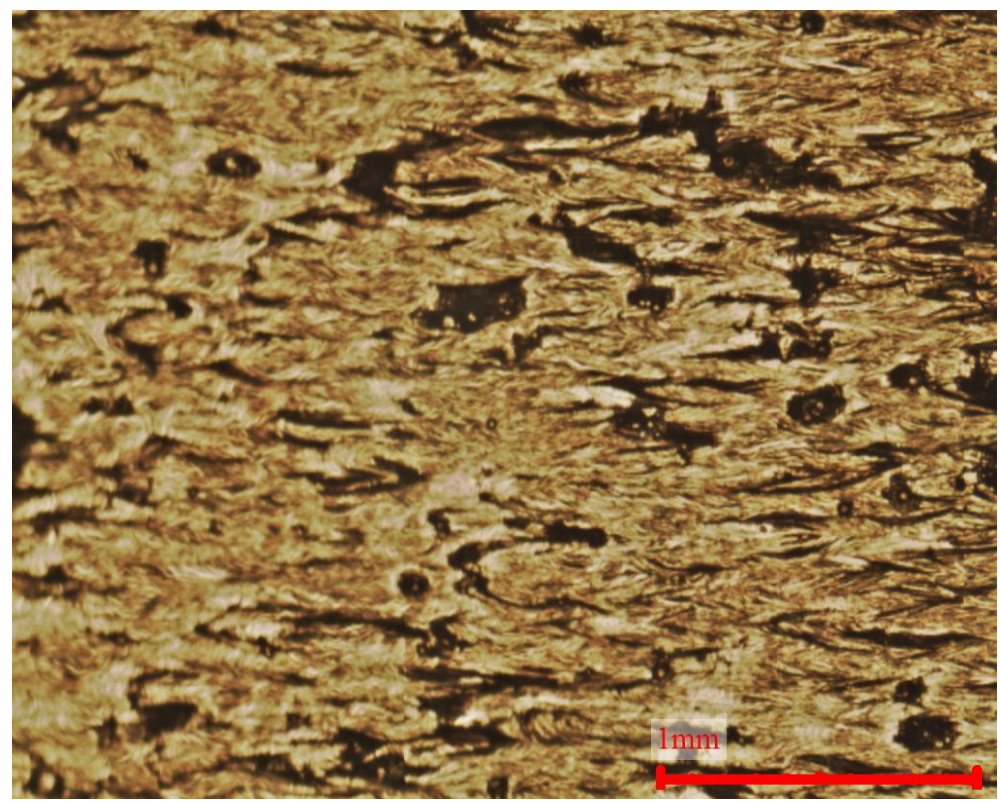

Figure 8 Surface of a bar produced with parallel scanning strategy(control case)

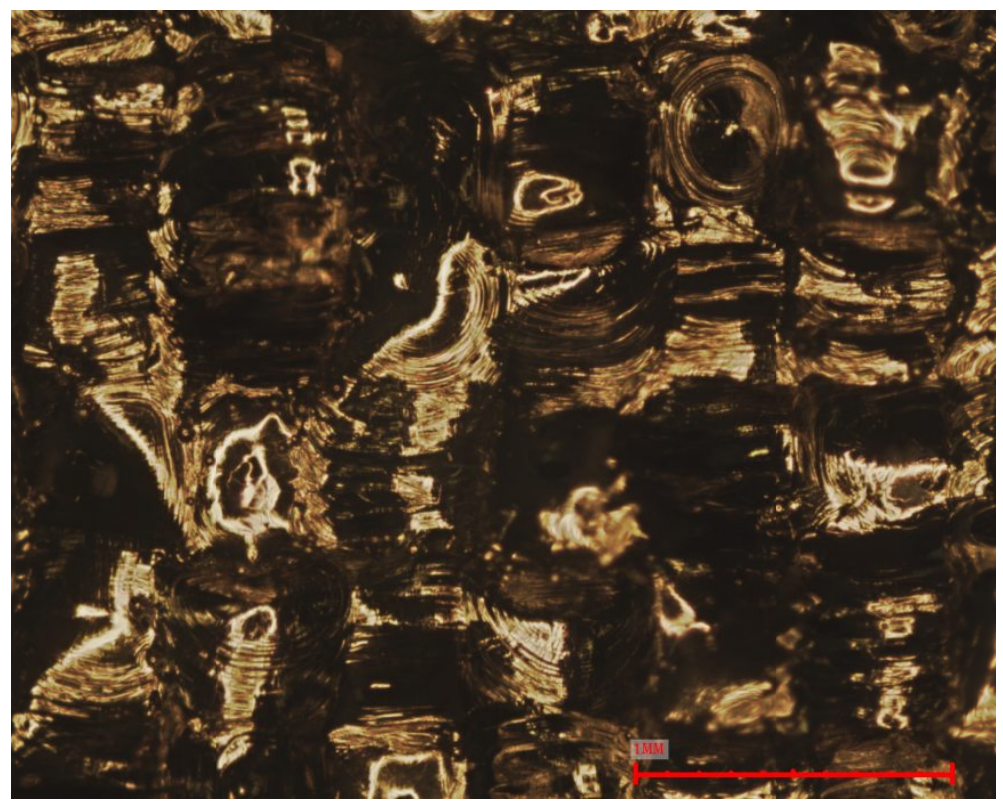

Figure 9 Surface of a bar produced using an optimized cellular scanning strategy

\section{CONCLUSION}

A calibrated, fast, hybrid thermal model coupled with a 3D finite element mechanical model was used to simulate residual stress formation and deformations during selective laser melting. The resulting reduction in computation time allowed numerical model based optimization of the cellular scanning strategy. Optimization of cellular scanning strategy was formulated into a quantifiable problem, and then simplified into two simultaneous sub-problems. A multilevel, multiscale optimization algorithm was adopted using a customized genetic algorithm with an objective of reducing residual stresses and deformations through prediction and 
improvement of thermal markers/indicators. The resulting thermo-mechanically optimized cellular scanning strategies were used to manufacture standard samples along with several control cases (scanning strategies). The optimized cellular scanning strategy based components showed lower distributed levels of deformations as compared to control cases showing higher localized deformations. Comparison of surface characteristics showed a better consolidation in optimized cellular scanning strategy based parts albeit at a cost of greater surface roughness brought about through balling effect in certain unit cells.

\section{ACKNOWLEDGEMENTS}

The authors of the paper acknowledge the contributions of the FMAT consortium and the Danish Technological Institute which provided the facilities for manufacturing the optimized scanning strategies.

\section{REFERENCES}

[1] R. Mertens, S. Clijsters, K. Kempen og J. Kruth, »Optimization of Scan Strategies in Selective Laser Melting of Aluminum Parts With Downfacing Areas, « J. Manuf. Sci. Eng., årg. 136, nr. 6, 2014.

[2] T. Antignac, J. Jhabvala, E. Boillat og R. Glardon, »On the effect of scanning strategies in the selective laser melting process, « Virtual and Physical Prototyping, årg. 5, nr. 2, pp. 99-109, 2010.

[3] K. Dai og L. Shaw, »Finite element analysis of distortion minimization in layer by layer laser processed components, « Proceedings of SRPM, pp. 29-39, 2002.

[4] B. E. A. T. G. R. Jhabvala J., »Study and simulation of different scanning strategies in SLM, « i Innovative Developments In Design And Manufacturing, Taylor \& Francis Group, 2010, pp. 369-375.

[5] R. Stamp og P. Fox, »The development of a scanning strategy for the manufacture of porous biomaterials by selective laser melting, « Journal of Material Science, pp. 1839-1849, 2009.

[6] C. Hauser og T. Childs, »Raster scan selective laser melting of the surface layer of a tool steel powder bed, « Proceedings of the National Academy of Sciences of the United States of America, årg. 103, nr. 4, pp. 379-384, 2006.

[7] B. Qian, F. Han, Y. Shi og Q. Wei, „Comparison of two scan strategies applied to the selective laser melting, « i International Conference on Computer Application and System Modelling, 2010.

[8] Y. Shi, Q. Wei, B. Qian og H. Wang, »The helix scan strategy applied to the selective laser melting, « International Journal of Advanced Manufacturing Technology, årg. 63, nr. 5-8, pp. 631-640, 2012.

[9] E. Yasa, J. Deckers, J. Kruth, M. Rombouts og L. J, »Investigation of sectoral scanning in selective laser melting, « ASME 2010 10th Bennial Conference on Engineering Systems Design and Analysis, årg. 4, pp. 695-703, 2010.

[10] W. Zhang, Y. Shi, B. Liu, L. Xu og W. Jiang, »Consecutive sub-sector scan mode with adjustable scan lengths for selective laser melting, «International Journal of Advanced Manufacturing Technology, årg. 41, nr. 7-8, pp. 706-713, 2009. 
[11] O. Rehme og C. Emmelmann, »Reproducibility for properties of selective laser melting products, « Proceedings of 3rd International WLT Conference on Lasers in Manufacturing, pp. 227-232, 2005.

[12] K. Zeng, D. Pal and B. Strucker, "A review of thermal analysi methods in Laser sintering and Selective laser melting," in Proceedings of the 23rd Annual International Solid Freeform Fabrication Symposium, Austin, USA, 2012.

[13] S. Mohanty og J. Hattel, »Cellular Scanning Strategy for Selective Laser Melting: Capturing Thermal Trends with a Low-Fidelity, Pseudo-Analytical Model, « Mathematical Problems in Engineering, årg. 2014, nr. Article ID 715058, p. 14 pages, 2014.

[14] L. Papadakis, A. Loizou, S. Bremen og J. Schrage, »A computational reduction model for appraising structural effects in selective laser melting manufacturing, "Virtual and Physical Prototyping, årg. 9, nr. 1, pp. 17-25, 2014.

[15] I. Yadroitsev og A. Gusarov, »Single track formation in selective laser melting of metal powders, « Journal of Materials Processing Technology, pp. 1624-1631, 2010.

[16] F. Gürtler, M. Karga, K. Leitza and M. Schmidt, "Simulation of laser beam melting of steel powders using the three-dimensional volume of fluid method," Physics Proceesia, vol. 41, pp. 874-879, 2013.

[17] A. Gusarov og Y. I., »Heat transfer modelling and stability analysis of selective laser melting, « Applied Surface Science, pp. 975-979, 2007.

[18] S. Mohanty og J. Hattel, »A finite volume volume alternate direction implicit approach to modelling selective laser melting, « i Proceedings of 32nd International Congress on Applications of Lasers and Electro-optics, 2014.

[19] S. Mohanty, C. Tutum og J. Hattel, »Cellular scanning strategy for selective laser melting: evolution of optimal grid-based scanning path and parametric approach to thermal homogeneity, « i Proceedings of SPIE 8608, Laser-based Micro- and Nano-packaging and Assembly VII, San Francisco, USA, 2013.

[20] A. Gusarov og P. M., »Residual stresses at laser surface remelting and additive manufacturing, «Physics Proceedia, pp. 248-254, 2011.

[21] M. Zaeh og B. G., »Investigations on residual stresses and deformations in selective laser melting, « Production Engineering, årg. 4, nr. 1, pp. 35-45, 2010.

[22] N. Contuzzi, S. Campanelli og A. Ludovico, »3D finitie element analysis in the selective laser melting process, « International Journal of Simulation Modelling, årg. 10, nr. 3, pp. 113-121, 2011.

[23] J. Hutchinson, »Generalizing J2 flow theory: Fundamental issues in strain gradient plasticity, « Acta Mechanica Sinica, årg. 28, nr. 4, pp. 1078-1086, 2012.

[24] H. Braun, »On solving travelling salesman problems by genetic algorithms, « Parallel Problem Solving from Nature, årg. 496, pp. 129-133, 2005. 